\title{
Research on the Causes and the Policies of Poverty in Rural China
}

\author{
Shuyang Zhang ${ }^{1 *}$ \\ ${ }^{1}$ Xi'an Gaoxin No.1 High School, Xi'an, Shaanxi, 710100, China \\ *Corresponding author.Email: Shuyangbetty@gmail.com
}

\begin{abstract}
This article analyzes the factors that lead to population poverty in rural China areas from the perspectives of natural conditions, ideological awareness and educational resources: the relatively closed natural conditions lead to the imperfect infrastructure; the outdated smallholder economic consciousness prevents people from seizing the opportunity of market economy; limited urban and rural educational resources lead a lack of awareness of the importance of education. This article also recommends corresponding policies: increasing infrastructure investment, identifying and assisting the poor, optimizing the education investment system, and increasing investment of infrastructure in poor areas.
\end{abstract}

Keywords: Stochastic model checking, assume-guarantee reasoning, symmetric assume-guarantee rule, learning algorithm, probabilistic automata

\section{INTRODUCTION}

Poverty has many negative effects. First, poverty makes it difficult to improve the overall economic strength of a country; second, poverty will cause backward ideological concepts and low civic quality, and seriously affect the popularity of education; third, poverty increases social instability and inequality of status. When the People's Republic of China was found, the poverty population was large and the overall economic level was low. Since the reform and opening up four decades ago, China's anti-poverty process has gone through five stages successively: generalized poverty alleviation under the planned economy system, large-scale poverty alleviation under the system reform, development-oriented poverty alleviation during the period of rapid economic growth, poverty alleviation and development at the beginning of the 21 st century, and targeted poverty alleviation after the 18th National Congress of the CPC. This multi-dimensional empirical anti-poverty model has gradually lifted China out of poverty, reduced the gap between the rich and the poor, achieved rapid economic growth and made remarkable achievements, and made outstanding contributions to the cause of global poverty reduction. However, at present, there are still many areas in the world deeply trapped in poverty. In view of the outstanding results of China's poverty alleviation, this article will discuss the factors that generate poverty in rural areas in China and its related policy enlightenment, trying to have certain reference significance for poverty alleviation in other countries in the world.

\section{LITERATURE REVIEW}

There are mainly two aspects of literature which is closely related to this article. The first type of literature focuses on the factors of poverty. Fu Yulong et al [1] found that the factors affecting American poverty include: macroeconomic development, economic structural adjustment, and economic inequality and other economic factors; race, gender, and culture and other social factors; and political generosity of Democratic and Republican social welfare, limitation of welfare policies, etc. Wang Bo [2] used the survey data of 14 villages in Gansu Province to conduct a comprehensive analysis of the causes of poverty in rural areas from the perspectives of natural environment, family, market, cultural habits, and policies. Zhang Yongli and Lu Xiao [3] based on the multidimensional poverty theory and the actual situation of rural poverty in China, based on the establishment of a multidimensional poverty and cause identification system, using the social survey data of a poor village in Gansu Province in 2015 to calculate and identify the multidimensional poverty status of the village and conduct the probit regression analysis on the causes of 
poverty. $\mathrm{Hu}$ Zhengtian [4] has conducted a lot of research on the current poverty and anti-poverty theories at home and abroad at the macro level, summarized the concept of poverty and the factors of poverty from the aspects of system, culture, and rights, and listed various anti-poverty theories. Jiang Xuan [5] analyzed the causes of poverty in contiguous destitute areas from the perspective of Krugman's geographic nature. Huomandu Siqin [6] used questionnaire survey and literature research methods to study the causes of poverty of Mongolian farmers and poverty alleviation measures. Gao Linqing [7] summarized the reasons for the ethnic minorities in the Xing'an League in the long-term poverty from four aspects: income poverty, ability poverty, rights poverty and the difficulties encountered in the process of targeted poverty alleviation. An Yuejiao [8] used the current research method to analyze the basic environmental conditions, poverty status, reasons for poverty, and feasibility of development in the poor mountainous tourist town of Daba Township, and aimed at the reasons for poverty, relying on its natural and human resources, guided by market demand, and proposing the development path of tourist towns from the perspectives of function, industry, community, ecology, and mechanism. Fu Liyuan [9] analyzed the four-layer structure of China's anti-poverty strategy, that is, the causes of poverty can be divided into overall causes, structural causes, conditional causes and individual causes. Qian Xin Duo [10] adopted the method of literature review, questionnaire survey, field interview and mathematical statistics, and selected the poor people who were mainly supported in the development of targeted poverty alleviation in Zhaotong City as the research objects, and conducted an in-depth investigation of the production and living conditions of the poor, using SPSS software to conduct correlation analysis and deeply explore the causes of poverty among the poor.

The second type of literature aims to explore relevant measures against poverty. Fu Liyuan [9] pointed out that after building a moderately prosperous society, China needs to make timely adjustments to its anti-poverty strategy: it must adapt to changes in the international environment, adopting policies that promoting economic development, and continuing to improve the country's overall poverty alleviation level; the government needs to continue to take active measures to eliminate Structural poverty and changing conditional poverty; when the government further improves the social assistance system, it can also delegate the work of reducing individual poverty in social organizations. Zhu Yingjie [11] put forward specific suggestions on Zhangjiakou's poverty alleviation to ensure that the poverty alleviation goals and tasks are completed on schedule, and to strengthen the poverty alleviation through strengthening the construction of grassroots party organizations. Luo
Jinhong [12], this paper discusses how to secure the achievements of poverty, prevent Chinese poverty and relative poverty problem, namely to five measures: strengthen the construction of grass-roots party organizations, stimulate the poor masses endogenous motivation, improving the capacity of grassroots infrastructure and basic public services for the poor and the industrial quality, and the efficiency, implement "accurate Chinese insurance". Chen Jie [13] discussed how to guarantee the effect of poverty alleviation and prevent the return of poor households in the postpoverty alleviation era, that is, according to the logic of "putting forward problems, combining theories, analyzing problems, exploring causes and proposing countermeasures". Gao Jie and Guo Xiaoming [14] explored the implementation of poverty alleviation policies and measures that are more in line with actual characteristics and real needs to achieve poverty alleviation and sustainable development in deeply impoverished areas. Bai Weijun and Wang Yijun [15] explained that in the anti-poverty in rural areas, my country has experienced policy changes from poverty alleviation to poverty alleviation through development, to poverty alleviation and targeted poverty alleviation. Shi Haibo and Lv Kaiyu [16] found that after 2020, toplevel designers attach great importance to the research and planning of anti-poverty strategic thinking after 2020 , focusing on the strategic coordination of rural revitalization and poverty alleviation, and on poverty return and relative poverty, multidimensional poverty, urban and rural poverty. In terms of mechanism design, we are continuing to consolidate the results of poverty alleviation, planning to adjust poverty standards and specific implementation paths. Wang Zelin [17] summarized the difficulties and constraints faced by Xintai City's precision poverty alleviation tasks through the analysis of the work measures and effectiveness of the precision poverty alleviation work, and put forward countermeasures and suggestions to solve the difficulties on this basis.

Based on the existing literature above, the contributions of this article are mainly reflected: first, in terms of research objects, this article focuses on analyzing rural areas in China; second, in terms of research ideas, it explores China from three levels of natural conditions, ideology and education Poverty factors in rural areas, and proposed corresponding measures.

\section{THE FACTOR ANALYSIS OF POVERTY}

\subsection{Natural Reasons}

This is an important part of the development of the poor areas. According to studies, $70 \%$ of people who did not solve the problem of food and clothing lived in countries with poor transport; nearly $7,000,000$ people even lived in areas with poor living conditions. The 
patchy transportation and poor condition blocked the development of poverty-stricken regions.

\subsubsection{Adverse ecological and natural environment}

In impoverished areas, because of fragile ecological environments, such as bad weather, lack of natural resources and so on, the economic development level is low. And combined with reasons in all aspects, it is difficult for people to move out of the poor area, so they have to live in such a bad environment which means that they lose the chance to develop and accumulate wealth, and conduct limited production instead of expanded production. The result is that this phenomenon seriously constrains local economic development.

\subsubsection{Geographical isolation}

The second reason is the geographical isolation of the poor region. Firstly, the location in the remote causes the traffic inconvenience and lack of infrastructure. It is quite difficult to finance for the transportation in the areas. Most of the poor areas are distributed in the remote mountain range or the border area. The long distance makes the exchange of information, logistics at a slow rate. Due to the information block, the local speciality can not be known by the people living the other place. Also, the inconvenience of logistics makes relatively low sales on the online shopping platforms.

\subsection{Ideological reasons}

\subsubsection{Conservative awareness of natural economy}

People in poor areas sometimes refuse to change and to make progress. They only see their impoverished sides instead of the advantage themselves and the development prospect. Facing the opportunity brought by the revolution of the market economy, they are willing to develop but they are also afraid of taking risks, so they missed the good chance to develop unfortunately.

\subsubsection{Feudal thought}

Feudal ideas such as "son preference" and "raise more children and enjoy more happiness". Some people in rural areas still have a very serious feudal ideology. In many places, they "prefer sons over daughters" and have more children until they have sons. This vicious cycle of "the more they are born, the poorer they become" has led to a persistent poverty in many areas, and even a tendency to become poorer. Bringing up sons to support parents in their old age is also a very common awareness among people. Therefore, the rapid population growth has offset the economic growth to a considerable extent.

\subsubsection{No long-term developmental vision}

Many leading cadres in poverty-stricken areas do not have a long-term vision for development. They only see immediate benefits instead of the long-term ones. For the investment that was already attracted, they did not make full use of the funds and resources to develop the local economy. However, they raise the price in order to obtain more benefits. As a result, the investors were reluctant to continue cooperation with that certain country, so the poverty has not been alleviated.

\subsection{Educational Reasons}

The backward education awareness is the main reason for restricting educational development in poor areas one. Still now, many people in poverty-stricken areas are not equipped with the correct view of education. Specifically, they did not fundamentally realize the importance of education. People in the area always upheld the notion that study was useless because of short-sightedness. The concept of looking up to men and down on women is deeply ingrained inside their head. People think it is a waste of money to allow girls to go to school. The better choice is to come into and work in the city in order to earn money. In povertystricken areas, there is a survey about teachers willingness to work in countries if they have the chance to transfer. The result is as many as $44.8 \%$ of the respondents who changed their careers when they were in school, and only those who were willing to continue to be teachers accounted for $38.3 \%$; indifferent accounted for $16.9 \%$. The lack of education also brings another problem: the low quality of labor. Because of the lack of education, although some youngsters come into cities and find jobs, the jobs they find are unskilled. For people who do these jobs, the accumulation of wealth is relatively slow. And it is difficult for them to transform from poverty to a better living standard.

\section{THE POLICIES OF POVERTY}

\subsection{Infrastructure}

Basic infrastructure has great impact on physical distribution. The perfect logistics distribution system is really needed with the network sale. If the rural logistics system is not sound, transportation problems will negatively effect villagers' career and incomes. Due to the partial rural areas are generally in the remote areas, some products, such as vegetables and fruits, are easy to be unfresh, and the lack of chain logistics directly increase the loss of products in the transport process, increase the cost of electricity sales. Therefore, 
government should attract the investment to build the basic infrastructure for the rural area.

\subsection{Poverty Alleviation}

\subsubsection{Identify the poor households}

By evaluating and comparing the housing condition, income level, labor forces and schooling level, township government identify the poor households in every town and countries. In order to make a dramatic management, leaders in the township government need to use the topdown decomposition and bottom-up step by step a baseline combination of determination and correction overtime. The selection need all villagers to to participate in in order to carry out the principle of democracy which is part of the recognition program. By investigating a baseline and conducting democratic appraisal preliminary to determine the list of poor household, villagers will not have objection to determine the final recipients. It can both identify the real poor and mobilize villagers to participate in.

\subsubsection{Open the career and build the local brand}

For production process in the rural, products production and processing points are scattered. Because it is difficult to form scale and make standard production, producers can not promise products quality with unified standard. In the other hand, the cost of production have space to reduce.

\subsection{Education}

\subsubsection{Optimize the education investment system and marketize the education in the poor area}

Lack of educational resources is the main restricting factor for the development of education in poor areas. According to the existing social background, it is quite difficult for the education in the poor area to alleviate the poor, and it is poor to optimize the educational investment system and marketize the education in the poor area.

First of all, improving the educational investment system, including the cost compensation system and the educational tax system. This improvement can ensure the fundamental stability and reliability of the education funds in the poor areas. At the same time, we should search for new ways of financing by means of positive explorations is needed in addition to strengthening and reinforcing the present source of education funding. Expand source channels of funds, diversifying investment subjects and improving efficiency of investing have great help in solving it. For example, raising financial education funds, establishing educational savings, educational lottery and so on.

\subsubsection{Using modern information technology, starting the educational information age in poor area.}

Distance learning is a new method of education as the modern information technology developed. It is a kind of teaching way that is opposite to face-to-face education. It is of cross-school and cross-regional education system and teaching mode. There are some of the advantages of the new educational form. It can break through the limitation of time and space, provide more learning opportunities, expand the scale of teaching, reduce the cost of teaching and balance the teaching resources. According to the benefits above, the distance learning has been recognized the importance and the broad prospects of developing distance education.

\subsubsection{Improving the schools conditions}

Focus on improve the weakness of rural schools running conditions, governors made solid progress in improving basic conditions in poor region education and obligated education standardization in schools' construction. By 2017, the rural poor areas high school classroom, tables and chairs, books, sports grounds and other teaching facilities to meet the basic requirements of teaching dormitory, beds, bathroom, dining room, water and other basic daily necessities. By 2020 , all the rural schools' conditions achieve the goal of the provincial level compulsory schools' education standards.

\subsubsection{Develop vocational education for get rid of poverty and become better off}

Vocational education is established for people to get the education of professional knowledge, skills and ethics needed by a certain occupation. This kind of education focuses much more on the practical skills and practical working ability. After gaining skills, people have speciality and are able to find jobs and earn money.

\section{CONCLUSION}

This article analyzes the causes of poverty in rural China from the perspectives of natural conditions, ideology and education, and it also proposes effective solutions and policies. From an objective point of view, due to the imperfect infrastructure caused by the relative isolation of natural conditions, the poor areas have infrequent exchanges of economic ideas with the outside world and cannot keep up with the times. Second, the outdated economic awareness of small farmers prevents people from seizing the business opportunities and making profits in the market economy. Third, the limited urban and rural educational resources and a lack of awareness of the importance of education have led to a low education rate. Therefore, people cannot change 
their destiny through gaining knowledge. The traditional patriarchal thoughts have also accelerated this phenomenon. This article also recommends corresponding policies. First, increasing infrastructure investment can help economic development. Second, identifying the poor for assistance to help the poor develop their careers, establish local brands, and promote the economic development of individuals and regions. Third, in terms of education, optimizing the educational investment system in poor areas and increasing infrastructure investment in poor areas can lay the foundation for economic development.

\section{REFERENCES}

[1] Y.L. Fu, J. Liu, W.J. Lu, Analysis of the causes of poverty in the United States from the perspective of Max Weber's social stratification theory, Chinese Administration 04(2015) 134-139.

[2] B. Wang, Research on the causes of current poverty in rural areas and anti-poverty countermeasuresBased on the survey data of 14 poor villages in Gansu, Financial Theory Research 05(2017) 33-42. DOI: 10.13894/j.cnki.jfet.2017.05.004.

[3] Y.L. Zhang, X. Lu, The identification of multidimensional poverty and its causes under the changing nature of poverty: Taking Liuhe Village, Gaolan County, Gansu Province as an example, Hubei Social Sciences, 06(2016)71-79. DOI: 10.13660/j.cnki.42-1112/c.013624.

[4] Z.T. Hu, Research on Precision Poverty Alleviation in Flower Arrangement Poor Areas of Hubei Province, Hubei Academy of Social Sciences, 2016. MA thesis.

[5] X. Jiang, Analysis of Poverty Factors in Contiguous Destitute Areas, East China Normal University, 2017. MA thesis.

[6] M.D.S.Q, Huo, Research on Poverty Causes and Poverty Alleviation Countermeasures of Mongolian Farmers in Zalaite Banner, Inner Mongolia Normal University, 2019. MA thesis.

[7] L.Q. Gao, Research on the Causes and Countermeasures of the Long-term Poverty of Minority Nationalities in Xing'an League of Inner Mongolia, Inner Mongolia University of Finance and Economics, 2016. MA thesis.

[8] Y.J. An, Research on the development of a poor mountainous tourist town in Daba Township, Qingchuan County, Chengdu University of Technology, 2016. MA thesis.

[9] L.Y. Fu, The four-tier structure of China's antipoverty strategy, Human Rights, 04(2020) 75-93. DOI: 10.16696/j.cnki.11-4090/d.2020.04.006.
[10] X.D. Qian, Research on the causes and countermeasures of poverty among the poor in Zhaotong City from the perspective of targeted poverty alleviation, Yunnan Normal University, 2020. MA thesis.

[11] Y.J. Zhu, Exploration of the role of grassroots party organizations based on decisive battles and decisive battles for poverty alleviation: Taking Zhangjiakou, a deeply impoverished area, as an example, Rural Economy and Technology, 31(12) (2020)139-140+151.

[12] J.H. Luo, Research on Measures to Consolidate Poverty Alleviation Achievements: Taking Dali Prefecture, Yunnan Province as an Example, China Development, 20(03) (2020)51-55. DOI: 10.15885/j.cnki.cn11-4683/z.2020.03.009.

[13] J. Chen, Research on anti-poverty countermeasures in J County, Shandong Province in the postpoverty era, Shandong University, 2020. MA thesis.

[14] J. Gao, X.M. Guo, Multiple challenges and policy choices in poverty governance in deeply impoverished areas, Journal of South-Central University for Nationalities (Humanities and Social Sciences Edition), 40(01) (2020)131-134.

[15] W.J. Bai, Y.J. Wang, China's rural anti-poverty policy changes and orientation observation." Inner Mongolia social sciences 41(05) (2020)173-179. DOI: $10.14137 /$ j.carol carroll nki issn10035281.2020.05.024.

[16] H.B. Shi, K.Y. lv, 2020 years anti-poverty strategy: discourse switch, top design and academic discussion, journal of China agricultural university (social science edition), 37(03) (2020)88-100. DOI: 10.13240 / j.carol carroll nki caujsse. 2020.03.009.

[17] Z.L. Wang, Research on practical Difficulties and Countermeasures of Targeted poverty Alleviation in Xintai city.2020. Shandong Agricultural University, MA Thesis. 